\title{
Identification of MicroRNAs Involved in Resistance to Sunitinib in Renal Cell Carcinoma Cells
}

\author{
NORIYA YAMAGUCHI ${ }^{1,2}$, MITSUHIKO OSAKI ${ }^{1,3}$, KUNISHIGE ONUMA ${ }^{1}$, \\ TETSUYA YUMIOKA ${ }^{2}$, HIDETO IWAMOTO ${ }^{2}$, TAKEHIRO SEJIMA $^{2}$, \\ HIROYUKI KUGOH ${ }^{3,4}$, ATSUSHI TAKENAKA ${ }^{2}$ and FUTOSHI OKADA ${ }^{1,3}$ \\ ${ }^{1}$ Division of Pathological Biochemistry and ${ }^{2}$ Department of Surgery, Division of Urology, Faculty of Medicine, \\ ${ }^{3}$ Chromosome Engineering Research Center, and ${ }^{4}$ Department of Biomedical Science, \\ Institute of Regenerative Medicine and Biofunction, Graduate School of Medical Science, \\ Tottori University, Tottori, Japan
}

\begin{abstract}
Aim: To generate sunitinib-resistant renal cell carcinoma $(R C C)$ cell lines and identify miRNAs contributing to sunitinib resistance. Materials and Methods: Two RCC cell lines, ACHN and RCC23, were cultured by continuous treatment with sunitinib for 3 months, with doses gradually increasing up to the 50\% inhibitory concentration for each cell line. We performed microarray and quantitative real-time polymerase chain reaction analyses of sunitinib-resistant ACHN (SR-ACHN) and RCC23 (SR-RCC23) cells, as well of as sunitinib-sensitive ACHN and RCC23 cells. Results: SR$A C H N$ and SR-RCC23 cells exhibited significantly higher resistance to sunitinib treatment compared to sunitinibsensitive cells. SR-ACHN and SR-RCC23 cells were hypertrophic and contained granules in the cytoplasm. When $S R-A C H N$ and SR-RCC23 cells were compared to ACHN and $R C C 23$ cells, expression of $m i R-575$, miR-642b-3p, and $m i R-$ 4430 was significantly increased, while that of miR-18a-5p, miR-29b-1-5p, miR-431-3p, and miR-4521 was significantly decreased. Conclusion: These miRNAs may contribute to sunitinib resistance in humans.
\end{abstract}

Targeted therapy with tyrosine kinase inhibitors (TKIs) is used as a treatment for metastatic renal cell carcinoma (mRCC). Among TKIs, sunitinib is indicated as a first-line therapy for mRCC and suppresses angiogenesis and tumor cell proliferation by binding and inhibiting vascular endothelial growth factor receptor (VEGFR) and platelet-derived growth

Correspondence to: Mitsuhiko Osaki, Ph.D., Division of Pathological Biochemistry, Faculty of Medicine, Tottori University, 86 Nishi-cho, Yonago 683-8503, Japan. Tel: +81 859386242, Fax: +81859386240, e-mail: osamitsu@med.tottori-u.ac.jp

Key Words: miRNA, renal cell carcinoma, sunitinib, tyrosine kinase inhibitor. factor receptor (PDGFR) (1). However, the clinical benefit of sunitinib in progression-free survival (PFS) is limited, and $\mathrm{mRCC}$ has a poor prognosis, with a median PFS of 11 months $(2,3)$. A major problem is that almost all patients experience relapse of disease due to acquired resistance to TKIs. Several resistance mechanisms for sunitinib have been proposed. For example, Tran et al. evaluated 22 known fibroblast growth factors (FGFs) in seven sunitinib-sensitive and sunitinibresistant RCC cell lines and showed that FGF1 is up-regulated in sunitinib-resistant cells (4).

MicroRNAs (miRNAs) are small non-protein-coding RNAs involved in cancer progression, metastasis, and resistance to antitumor drugs. miRNAs are approximately 22 nucleotides in length and regulate gene expression at the post-transcriptional level by binding to the 3' untranslated region of target mRNAs, leading to inhibition of translational or mRNA degradation (5). miRNAs play an important role as regulators of gene expression in tumorigenesis, tumor progression, and metastasis, and have been suggested as biomarkers for diagnosis and treatment response $(6,7)$. Some studies have reported a relationship between mechanisms of acquired resistance to sunitinib and miRNA expression in RCC cells $(7,8)$. However, these previous reports selected candidate miRNAs obtained from clinical tissues and serum. Generally, nephrectomy had been performed before starting sunitinib therapy. Candidate miRNAs were identified on the basis of therapeutic effect of sunitinib and the expression level of miRNAs extracted from clinical renal tissues. In the case of experiments using clinical renal tissues, it is difficult to capture the changes that have occurred in the process of becoming resistant to sunitinib therapy.

In the present study, we generated sunitinib-resistant RCC cell lines and selected candidate miRNAs associated with sunitinib resistance. We observed the direct effect of sunitinib on RCC cells in isolation, without the potentially confounding influence of the major resistance mechanisms of mRCC cells associated with vascular factors. 
We generated two sunitinib-resistant RCC cell lines by continuous treatment with sunitinib to detect candidate miRNAs implicated in the regulation of sunitinib resistance. If the therapeutic effect of sunitinib can be prolonged by regulating the miRNAs detected in this study, this could be epoch-making in the treatment strategy of mRCC.

\section{Materials and Methods}

Tumor cell lines. The parental human renal cell carcinoma cell lines ACHN (sunitinib-sensitive ACHN), which was purchased from the American Type Culture Collection (Rockville, MD, USA), and RCC23 (sunitinib-sensitive RCC23), which was established at National Cancer Center Research Institute in Japan, were cultured in RPMI-1640 (Thermo Fisher Scientific Inc., Waltham, MA, USA) with $10 \%$ fetal bovine serum (FBS) and $1 \%$ of PenicillinStreptomycin (Thermo Fisher Scientific Inc.). Sunitinib-resistant cells were generated by continuous exposure to sunitinib for 3 months, with gradually increasing doses of sunitinib up to the $50 \%$ inhibitory concentration $\left(\mathrm{IC}_{50}\right)$ for each cell line. The generated sunitinib-resistant cell lines (SR-ACHN and SR-RCC23) were subsequently used for experiments.

Cell proliferation assay. Cell proliferation of ACHN and SR-ACHN cells, as well as RCC23 and SR-RCC23 cells, was examined using a Cell Counting Kit 8 (Dojindo Molecular Technologies, Kumamoto, Japan). Cells $\left(5 \times 10^{3}\right)$ were seeded in each well of a 96well plate, and the number of cells was assessed at 72 hours for ACHN and SR-ACHN cells and at 48 hours for RCC23 and SRRCC23 cells.

Total RNA extraction and microarray analysis. Total RNA from ACHN, SR-ACHN, RCC23 and SR-RCC23 cells was extracted using a miR-Vana ${ }^{\mathrm{TM}}$ miRNA Isolation Kit (Thermo Fisher Scientific Inc.) according to the manufacturer's protocol. The concentration of total RNA samples of ACHN, SR-ACHN, RCC23 and SR-RCC23 cells was $1.84,1.01,0.65$ and $0.38 \mu \mathrm{g} / \mu \mathrm{l}$, respectively (final elution volume, $50 \mu \mathrm{l}$ ). Total RNA quantity and purity was determined using a NanoDrop ND-1000 spectrophotometer (Thermo Fisher Scientific Inc.). RNA samples were stored at $-80^{\circ} \mathrm{C}$ until reverse transcription (RT). For microarray analysis, total RNA was labeled using a 3D-Gene miRNA Labeling Kit (Toray Industries, Kamakura, Japan). Labeled RNA was hybridized to 3D-Gene human miRNA V21 chips (Toray Industries).

miRNA real-time polymerase chain reaction. From the microarray evaluation, miRNAs increased over 8-fold or decreased over 4-fold in SR-ACHN and SR-RCC23 cells compared with ACHN and RCC23 cells, respectively, were selected for further validation. RT was performed using a stem-loop RT Megaplex Primer Pool and TaqMan MicroRNA RT Kit (Thermo Fisher Scientific Inc.). RT reaction mixtures were incubated for $30 \mathrm{~min}$ at $16^{\circ} \mathrm{C}, 30 \mathrm{~min}$ at $42^{\circ} \mathrm{C}, 5 \mathrm{~min}$ at $85^{\circ} \mathrm{C}$ and then at $4^{\circ} \mathrm{C}$. Complementary DNAs (cDNAs) were pre-amplified using a Taqman Universal PCR Master Mix (Thermo Fisher Scientific Inc.). Quantitative RT-PCR (RTqPCR) assays were performed with an ABI 7900HT System (Applied Biosystems, Foster City, CA, USA) using primers contained in TaqMan miRNA Assays Kit matching selected miRNAs: $m i R-575$ (assay ID: 001617), $m i R-642 b-3 p$ (assay ID: 462949_mat), miR-4430 (assay ID: 465081_mat), miR-6076 (assay ID: 474248_mat), $m i R-6501-3 p$ (assay ID: 476038_mat), miR-18a$5 p$ (assay ID: 002422), $m i R-29 b-1-5 p$ (assay ID: 002165), $m i R-431$ $3 p$ (assay ID: 002312), and $m i R-4521$ (assay ID: 465004_mat) (all Applied Biosystems). Expression was normalized to that of U6B small nuclear RNA (RNU6B) (assay ID: 001093). The relative expressions of selected miRNAs were determined by the equation: $2^{-\triangle \mathrm{CT}}\left(\triangle \mathrm{CT}=\mathrm{C}_{\mathrm{T}}\right.$ selected miRNA $\left.-\mathrm{CT} R N U 6 B\right)$. All analyses were performed as specified in the manufacturer's protocols.

Analysis of predicted putative mRNA targets and Kyoto Encyclopedia of Genes and Genomes (KEGG) cancer pathways. We determined the validated mRNA targets of the differentially expressed miRNAs identified from the previous analyses using miR-TarBase (September, 2015 release, http://mirtarbase.mbc.nctu.edu.tw/), an experimentally validated miRNA-target interaction database (9). We also predicted the putative mRNA targets of the identified miRNAs using DIANAmicroT web server v5.0 enhanced with an improved target prediction algorithm, DIANA-microT-CDS (September, 2013 release, http://www.microrna.gr/microT-CDS.) $(10,11)$. Additionally, putative KEGGpathways (November, 2016 release, http://www.genome.jp/ $\mathrm{kegg} /$ ) of the identified miRNAs were identified using DIANA miRPath v2.0 (July, 2012 release, http://www.microrna.gr/ miRPathv2.) (12).

Statistical analyses. The parametric Student $t$-test was used for statistical analyses. All statistical analyses were performed using Easy R (EZR) software (Saitama Medical Center, Jichi Medical University, Saitama, Japan). A value of $p<0.05$ was considered statistically significant (13).

\section{Results}

Establishment of sunitinib-resistant $R C C$ cell lines. The $\mathrm{IC}_{50}$ of sunitinib for ACHN cells was $10 \mu \mathrm{M}$, and that for RCC23 cells $14 \mu \mathrm{M}$. SR-ACHN and SR-RCC23 cells exhibited significantly higher resistance to sunitinib treatment compared with sunitinib-sensitive cells (Figure 1A). SRACHN and SR-RCC23 cells were hypertrophic and contained some granules in their cytoplasm (Figure 1B).

miRNA microarray analysis. Two pairs of cell lines (ACHN and SR-ACHN, RCC23 and SR-RCC23) were used to identify miRNA candidates involved in regulating sunitinib resistance. miRNA microarray analyses were performed to compare ACHN with SR-ACHN cells and RCC23 with SRRCC23 cells. Fifteen miRNAs were found to be up-regulated by over 8 -fold, while 31 miRNAs were down-regulated over 4-fold in SR-ACHN compared with ACHN cells. Twentyfour miRNAs were up-regulated by over 8 -fold, while nine miRNAs were down-regulated over 4-fold in SR-RCC23 compared with RCC23 cells. Of these, five up-regulated miRNAs (miR-575, miR-642b-3p, miR-4430, miR-6076 and $m i R-6501-3 b)$ and four down-regulated miRNAs (miR-18a$5 p, m i R-29 b-1-5 p, m i R-431-3 p$ and $m i R-4521)$ were common to both sunitinib-resistant cell lines (SR-ACHN and SRRCC23), as shown in Table I. 
$\mathbf{A}$
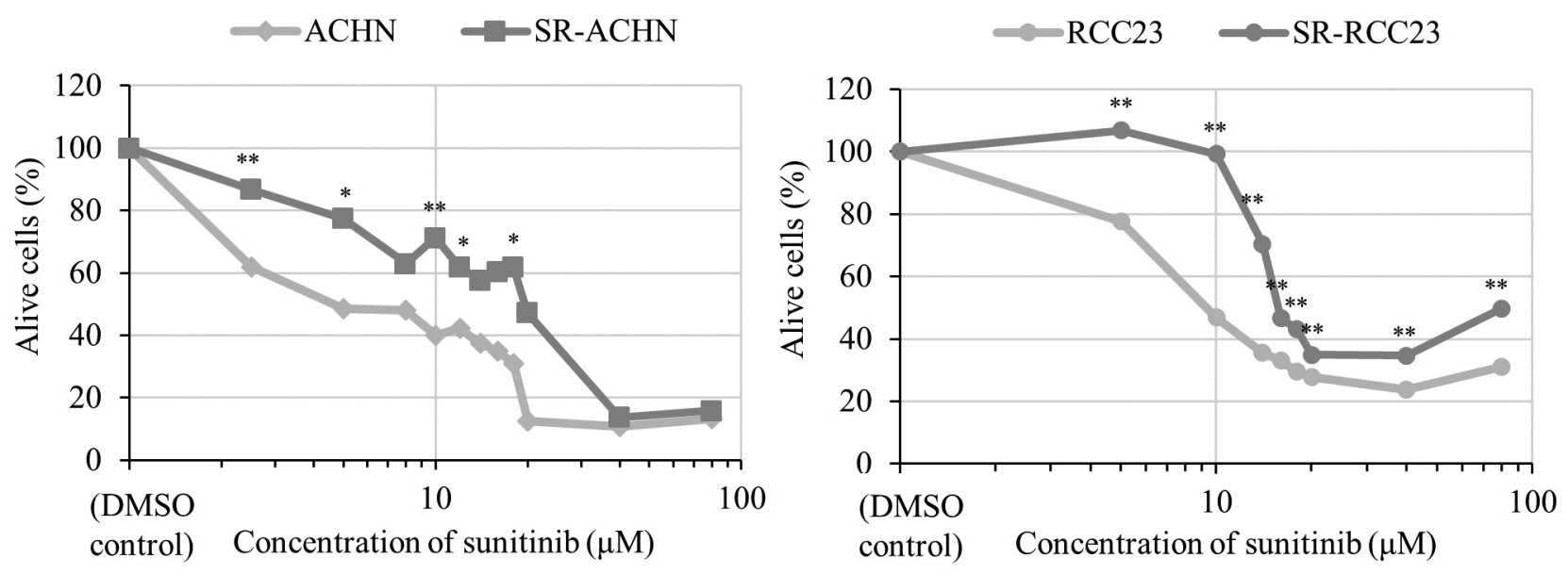

B
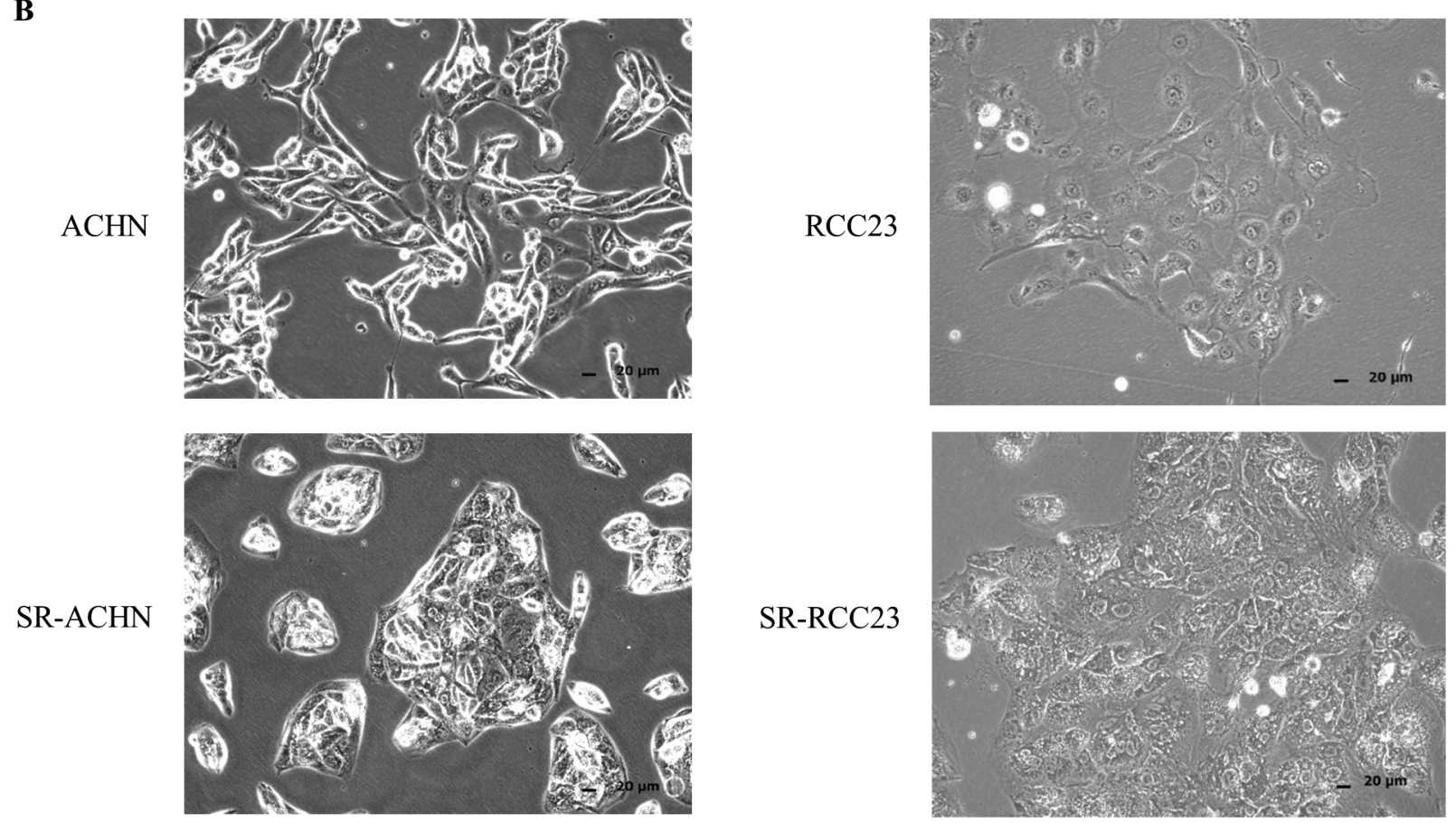

Figure 1. A: Effects of sunitinib treatment in vitro on cell growth. The 50\% inhibitory concentration of sunitinib for ACHN cells was $10 \mu \mathrm{M}$, and that for RCC23 cells, $14 \mu \mathrm{M}$. SR-ACHN and SR-RCC23 cells exhibited significantly higher resistance to sunitinib treatment compared to parental sunitinibsensitive cells. ${ }^{*} p<0.05, * * p<0.01$. B: Light microscopy of ACHN, RCC23, SR-ACHN and SR-RCC23 cells. Morphological changes were apparent in sunitinib-resistant ACHN and RCC23 cells. These cells were hypertrophic and contained some granules in the cytoplasm (original magnification, $\times 400$ ).

Validation of microarray data by real-time RT-qPCR. Based on the microarray results, we further examined the expression level of the five up-regulated miRNA and the four down-regulated miRNAs common to both cell lines using real-time RT-qPCR. RNA pools from the same RNA samples used for the microarray experiments were prepared. We used $R N U 6 B$ as a reference gene for normalization of the miRNA data. In SR-ACHN and SR-RCC23 cells compared with ACHN and RCC23 cells, respectively, the CT values of $m i R$ 575, $m i R-642 b-3 p$ and $m i R-4430$ were significantly increased 
Table I. MicroRNA expression in sunitinib-resistant (SR)-ACHN and SR-RCC23 cells increased by over 8-fold and reduced by over 4-fold compared to parental sunitinib-sensitive cells.

\begin{tabular}{|c|c|c|c|c|c|c|c|}
\hline \multirow[b]{2}{*}{ Difference ratio } & \multirow[b]{2}{*}{ Selected microRNA } & \multicolumn{3}{|c|}{ Cell line } & \multicolumn{3}{|c|}{ Cell line } \\
\hline & & $\mathrm{ACHN}$ & SR-ACHN & Fold-change & $\mathrm{RCC} 23$ & SR-RCC23 & Fold-change \\
\hline \multirow[t]{5}{*}{ Increased by $>8$-fold } & $\operatorname{miR}-575$ & 43.20 & 722.50 & 16.71 & 39.2 & 322.1 & 8.22 \\
\hline & $m i R-642 b-3 p$ & 156.30 & 1939.20 & 12.40 & 43.4 & 846.8 & 19.50 \\
\hline & $m i R-4430$ & 22.51 & 300.48 & 13.35 & 15.1 & 154.5 & 10.21 \\
\hline & $m i R-6076$ & 51.26 & 466.63 & 9.10 & 21.7 & 202.8 & 9.33 \\
\hline & $m i R-6501-3 p$ & 21.74 & 184.02 & 8.47 & 13.9 & 182.6 & 13.09 \\
\hline \multirow[t]{4}{*}{ Reduced by $>4$-fold } & $m i R-18 a-5 p$ & 161.24 & 28.67 & 0.18 & 73.7 & 17.3 & 0.23 \\
\hline & $m i R-29 b-1-5 p$ & 99.31 & 6.10 & 0.06 & 33.9 & 7.6 & 0.23 \\
\hline & $m i R-431-3 p$ & 125.87 & 28.64 & 0.23 & 73.2 & 9.0 & 0.12 \\
\hline & $m i R-4521$ & 321.06 & 38.62 & 0.12 & 88.2 & 19.5 & 0.22 \\
\hline
\end{tabular}

(Figure 2A), while those of $m i R-18 a-5 p$, miR-29b-1-5p, miR$431-3 p$, and $m i R-4521$ were significantly reduced (Figure 2B), consistent with the microarray data.

Predicted putative mRNA targets and cancer pathways. Computational analysis using DIANA-microT web server v5.0 was performed to predict putative target genes of the differentially regulated miRNAs identified in the previous experiments. We also predicted the putative cancer pathways associated with these miRNAs using DIANA miRPath (v2.0). According to miRTarBase, $m i R-4430$ is related to phosphatase and tensin homolog deleted on chromosome 10 (PTEN), while $m i R-18 a-5 p$ is related to hypoxia inducible factor 1 alpha (HIF1A) (9). According to the KEGG pathway identified using the DIANA miRPath (v2.0), miR-18a-5p is potentially related to endocytosis pathway-targeted lysosomal activity (12) (Table II).

\section{Discussion}

miRNAs play an important role as regulators of gene expression related to drug resistance and have been suggested as biomarkers of treatment responses $(7,8,14)$. Sunitinib is a TKI indicated as a first-line treatment for mRCC. However, many patients experience relapse of their disease due to acquired resistance to sunitinib $(15,16)$. To date, various miRNAs have been reported to contribute to sunitinib resistance. Merhautova et al. reported that decreased tissue levels of $m i R-155$ and $m i R-484$ were significantly associated with prolonged time to progression (17). Berkers et al. reported that $m i R-141$ down-regulationdriven epithelial-to-mesenchymal transition (EMT) in clear cell carcinoma was associated with an unfavorable response to sunitinib (8). These authors also reported that $m i R-141$ overexpression induces EMT reversal through inhibition of zinc finger E-box binding homeobox (ZEB) transcript factors
(8). Prior et al. screened 673 miRNAs in tumor tissues from patients with metastatic RCC and determined that higher miR-942 expression was an independent predictor of inadequate sunitinib efficacy (7). They described a paracrine mechanism through which high miR-942 levels in $\mathrm{mRCC}$ cells induced matrix metalloproteinase (MMP9) and VEGF secretion, and enhanced migration of and sunitinib resistance in endothelial cells (7). However, these previously described candidate miRNAs selected as targets of sunitinib resistance were based on data extracted from clinical tissues and serum. It is difficult to capture the changes that have occurred in the process of becoming resistant to sunitinib therapy.

In this study, we generated sunitinib-resistant cells and identified miRNAs associated with sunitinib resistance by performing microarray and RT-qPCR analyses. We identified seven miRNAs ( $m i R-575, m i R-642 b-3 p, m i R-4430, m i R-18 a-$ $5 p, m i R-29 b-1-5 p$, miR-431-3p, miR-4521) whose expressions were significantly increased or reduced in sunitinib-resistant cells. All these miRNAs are newly identified as being associated with sunitinib resistance. According to miRTarBase, $m i R-4430$ was reported to be associated with PTEN, a suppressor of the mammalian target of rapamycin (mTOR) signaling pathway that plays an important molecular role in RCC (9). $m i R-18 a-5 p$ was reported to be associated with HIF1A, which is another important molecular factor in the RCC pathway (9). According to miR-microT-CDS, FGF1, which has been proposed to be up-regulated in sunitinibresistant cell lines, is a predicted target of miR-18a-5p $(4,10$, 11). $m i R-4430$ was significantly increased in sunitinibresistant cell lines, while $m i R-18 a-5 p$ was significantly reduced, suggesting that acquisition of sunitinib resistance was associated with PTEN down-regulation, and FGF1 and HIF $1 A$ up-regulation promoted by increased expression of $m i R-4430$ and decreased expression of miR-18a-5p, respectively. $m i R-4521$ was also significantly decreased in sunitinib-resistant cells. According to miR-microT-CDS, $m i R$ - 
A
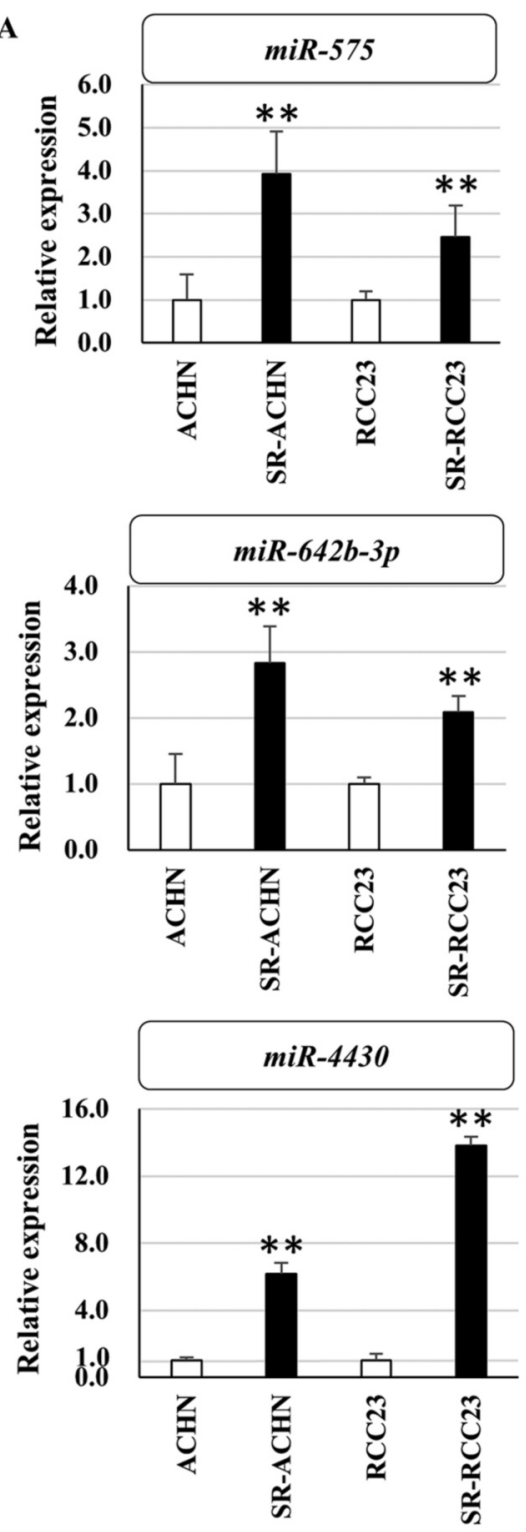

B
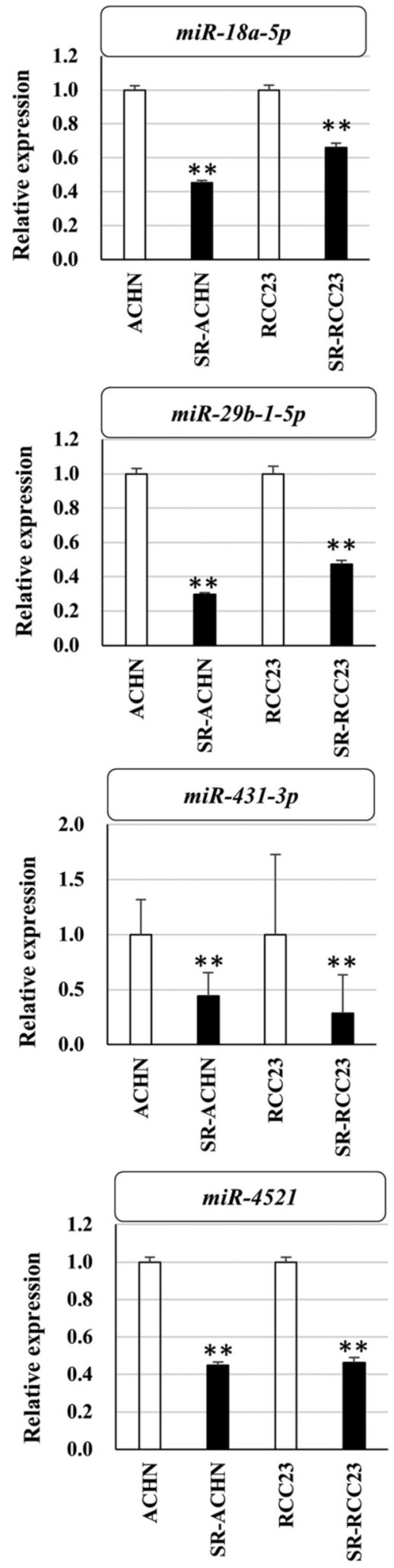

Figure 2. Quantitative miRNA levels in ACHN and RCC23 cells compared to SR-ACHN and SR-RCC23 cells. miRNA levels are represented as mean $2^{-\triangle C T} \pm S E$, with expression in sunitinib-sensitive cells as a reference. A: miRNAs significantly increased in sunitinib-resistant ACHN and RCC23 cells. B: miRNAs significantly decreased in sunitinib-resistant ACHN and RCC23 cells. ${ }^{* *} p<0.01$. 
Table II. Validated and predicted putative mRNA targets and predicted putative target pathways of identified microRNAs.

\begin{tabular}{|c|c|c|c|c|}
\hline & MicroRNA & $\begin{array}{l}\text { Validated mRNA } \\
\text { (miR-TarBase) }\end{array}$ & DIANA-microT-CDS & $\begin{array}{l}\text { Predicted targeted } \\
\text { KEGG pathway }\end{array}$ \\
\hline \multirow[t]{3}{*}{$\begin{array}{l}\text { Up-regulated in } \\
\text { resistant cells }\end{array}$} & $m i R-575$ & No validated mRNA targets & $\begin{array}{l}\text { DENND5A, RIPK4, } \\
\text { ZNF726, RSBN1 }\end{array}$ & No detection \\
\hline & $m i R-642 b-3 p$ & No validated mRNA targets & $\begin{array}{c}\text { TMPO, ARSB, } \\
L C N L 1, A T P 8 B 1\end{array}$ & $\begin{array}{l}\text { Transcriptional misregulation in } \\
\text { cancer, renal cell carcinoma, } \\
\text { prostate cancer, thyroid cancer }\end{array}$ \\
\hline & $m i R-4430$ & PTEN (9) & $\begin{array}{l}\text { SIK2, GM2A, } \\
\text { NFIB, BEND3 }\end{array}$ & $\begin{array}{l}\text { ERBB signaling pathway, MAPK signaling } \\
\text { pathway, mTOR signaling pathway, } \\
\text { cell cycle, pancreatic cancer, } \\
\text { non-small cell lung cancer }\end{array}$ \\
\hline \multirow[t]{4}{*}{$\begin{array}{l}\text { Down-regulated } \\
\text { in resistant cells }\end{array}$} & $m i R-18 a-5 p$ & HIF1A (9) & $\begin{array}{c}E P B 41 L 1, F G F 1 \\
H M B O X 1, M A P 7 D 1\end{array}$ & Endocytosis: lysosome \\
\hline & $m i R-29 b-1-5 p$ & No validated mRNA targets & $\begin{array}{c}\text { NEUROD1, EWSR1, } \\
\text { ANKRD36C }\end{array}$ & $\begin{array}{l}\text { Transcriptional misregulation in cancer, } \\
\text { HIF1 signaling pathway, } \\
\text { PI3K-AKT signaling pathway }\end{array}$ \\
\hline & $m i R-431-3 p$ & No validated mRNA targets & $\begin{array}{l}\text { INTS1, SPATA5L1, } \\
\text { PPIL2, STXBP1 }\end{array}$ & Ubiquitin mediated proteolysis \\
\hline & $m i R-4521$ & No validated mRNA targets & $\begin{array}{l}\text { GABARAPL2, PRTG } \\
\text { GCM1, ZEB2 (8) }\end{array}$ & $\begin{array}{l}\text { VEGF signaling pathway, } \\
\text { MAPK signaling pathway, } \\
\text { HIF1 signaling pathway, mTOR } \\
\text { signaling pathway, pancreatic cancer, } \\
\text { renal cell carcinoma, prostate cancer, } \\
\text { non-small cell lung cancer }\end{array}$ \\
\hline
\end{tabular}

KEGG, Kyoto Encyclopedia of Genes and Genomes; MAPK, mitogen-activated protein kinase; mTOR, mammalian target of rapamycin; PI3K, phosphoinositide 3-kinase; VEGF, vascular endothelial growth factor; HIF, hypoxia inducible factor.

4521 is reported to be associated with ZEB2, a proposed factor involved in the acquisition of sunitinib resistance via induction of EMT $(8,10,11)$.

According to KEGG pathway analyses, miRNAs identified in this study could be related to the critical molecular pathways of RCC and several other cancer types, including the mitogen-activated protein kinase (MAPK) and mTOR pathways ( $m i R-4430, m i R-4521)$, VEGF pathway ( $m i R-4521)$, phosphatidylinositol 3-kinase-AKT serine/threonine kinase (PI3K-AKT) pathway (miR-29b-1-5p), and HIF1 pathway (miR-29b-1-5p, miR-4521) (12). These miRNAs have also been associated with specific cancer types, including RCC and prostate cancer $(m i R-642 b-3 p, m i R-4521)$, as well as pancreatic cancer and non-small cell lung cancer $(m i R-4430$ and $m i R-4521)$ (12). Interestingly, according to KEGG pathway analysis, $m i R-18 a-5 p$ could be related to endocytosis pathway-targeted lysosome activity. Ellegaard et al. reported that MCF7 breast cancer cells treated with sunitinib showed a strikingly altered morphology in extracts of luminal material and a poorly-defined outer lysosomal membrane (18). The authors also reported that sunitinib did not alter the organelle morphology of mitochondria, endoplasmic reticulum, or the Golgi apparatus, supporting the direct action of sunitinib on endolysosomal components (18). Gotink et al. reported that continuous exposure to sunitinib increased lysosomal capacity in 786-O RCC cells and HT-29 pancreatic cancer cells by performing light microscopy and immunofluorescent staining with $\beta$-actin and Hoechst, and that despite higher intracellular sunitinib accumulation, levels of the key signaling factors $\mathrm{p}-\mathrm{AKT}$ and phospho-extracellular signal-regulated kinases (p-ERK) were unaffected. On the point of morphology, sunitinib-resistant cells appeared hypertrophic and had enlarged nuclei compared to that of their parental cells (19). We similarly observed that sunitinibresistant cells showed a bloated appearance and contained granules (Figure 1B). The granules we observed may also be sunitinib, which was taken up abundantly in lysosomes of resistant cells. Giuliano et al. reported that sunitinib-resistant 786-O RCC cells formed larger colonies, accumulated larger vacuolar structures, displayed incomplete autophagy, and showed increased migration ability compared with parental sunitinib-sensitive 786-O RCC cells (20).

According to KEGG pathway analysis, miR-431-3p could be associated with ubiquitin-mediated proteolysis. Giuliano et al. reported that proteasome inhibitors induced the death of sunitinib-resistant cells, suggesting that the ubiquitinproteasome system compensates for inhibition of autophagy to maintain homeostasis (20). Sakai et al. reported that the 
important pathways in RCC progression, including the PI3KAKT and MAPK signaling pathways, remained active in sunitinib-resistant cells, even in the presence of sunitinib (21). From previous reports, other mechanisms like FGF1 signaling, lysosomal degradation, and ubiquitin-mediated proteolysis through miRNA regulation may have important roles in sunitinib resistance. It will be necessary to further verify the relation between $m i R-18 a-5 p$ regulation of FGF1 signaling and sunitinib resistance.

In summary, we generated two sunitinib-resistant RCC cell lines, that enabled the study of the effects of sunitinib on cancer cells in isolation, without the influence of in vivo sunitinib-associated anti-angiogenesis mechanisms. Gotink et al. quantified microvessel density as a measure of angiogenesis in vivo in a trial using sunitinib-sensitive HT-29 and sunitinibresistant HT-29 cells. Although microvessel density was significantly reduced in both tumor types, the proliferation of sunitinib-resistant HT-29 tumor cells was unaffected, and the cells displayed continued growth compared with sunitinibsensitive HT-29 tumor cells (22). It will be necessary to verify the relation between the studied miRNAs and each putative target mRNA and signaling pathway in vivo using the cell lines generated in the present study.

In conclusion, we generated sunitinib-resistant cell lines and identified miRNAs associated with sunitinib resistance. Targeting of these altered miRNAs could contribute to the development of approaches to reduce sunitinib resistance and improve the prognosis of patients with $\mathrm{mRCC}$.

\section{References}

1 Mendel DB, Laird AD, Xin X, Louie SG, Christensen JG, Li G, Schreck RE, Abrams TJ, Ngai TJ, Lee LB, Murray LJ, Carver J, Chan E, Moss KG, Haznedar JO, Sukbuntherng J, Blake RA, Sun L, Tang C, Miller T, Shirazian S, McMahon G and Cherrington JM: In vivo antitumor activity of SU11248, a novel tyrosine kinase inhibitor targeting vascular endothelial growth factor and platelet-derived growth factor receptors: determination of a pharmacokinetic/pharmacodynamic relationship. Clin Cancer Res 9: 327-337, 2003.

2 Motzer RJ, Hutson TE, Tomczak P, Michaelson MD, Bukowski RM, Oudard S, Negrier S, Szczylik C, Pili R, Bjarnason GA, Garcia-del-Muro X, Sosman JA, Solska E, Wilding G, Thompson JA, Kim ST, Chen I, Huang X and Figlin RA: Overall survival and updated results for sunitinib compared with interferon alfa in patients with metastatic renal cell carcinoma. J Clin Oncol 27: 3584-3590, 2009.

3 Motzer RJ, Bacik J and Mazumdar M: Prognostic factors for survival of patients with stage IV renal cell carcinoma: Memorial Sloan-Kettering Cancer Center experience. Clin Cancer Res 10: 6302-6303, 2004.

4 Tran TA, Leong HS, Pavia-Jimenez A, Fedyshyn S, Yang J, Kucejova B, Sivanand S, Spence P, Xie XJ, Peña-Llopis S, Power $\mathrm{N}$ and Brugarolas J: Fibroblast growth factor receptor-dependent and -independent paracrine signaling by sunitinib-resistant renal cell carcinoma. Mol Cell Biol 15: 1836-1855, 2016.
5 Slaby O, Jancovicova J, Lakomy R, Svoboda M, Poprach A, Fabian P, Kren L, Michalek J and Vyzula R: Expression of miRNA-106b in conventional renal cell carcinoma is a potential marker for prediction of early metastasis after nephrectomy. $\mathrm{J}$ Exp Clin Cancer Res 29: 90, 2010.

6 Iwamoto H, Kanda Y, Sejima T, Osaki M, Okada F and Takenaka A: Serum miR-210 as a potential biomarker of early clear cell renal cell carcinoma. Int J Oncology 44: 53-58, 2014.

7 Prior C, Perez-Gracia JL, Garcia-Donas J, Rodriguez-Antona C, Guruceaga E, Esteban E, Suarez C, Castellano D, del Alba AG, Lozano MD, Carles J, Climent MA, Arranz JA, Gallardo E, Puente J, Bellmunt J, Gurpide A, Lopez-Picazo JM, Hernandez AG, Mellado B, Martínez E, Moreno F, Font A and Calvo A: Identification of tissue microRNAs predictive of sunitinib activity in patients with metastatic renal cell carcinoma. PLoS One 9: e86263, 2014.

8 Berkers J, Govaere O, Wolter P, Beuselinck B, Schöffski P, van Kempen LC, Albersen M, Van den Oord J, Roskams T, Swinnen J, Joniau S, Van Poppel H and Lerut E: A possible role for microRNA-141 down-regulation in sunitinib resistant metastatic clear cell renal cell carcinoma through induction of epithelialto-mesenchymal transition and hypoxia resistance. J Urol 189: 1930-1938, 2013.

9 Chou CH, Chang NW, Shrestha S, Hsu SD, Lin YL, Lee WH, Yang CD, Hong HC, Wei TY, Tu SJ, Tsai TR, Ho SY, Jian TY, Wu HY, Chen PR, Lin NC, Huang HT, Yang TL, Pai CY, Tai CS, Chen WL, Huang CY, Liu CC, Weng SL, Liao KW, Hsu WL and Huang HD: miRTarBase 2016: Updates to the experimentally validated miRNA-target interactions database. Nucleic Acids Res 44: 239-247, 2016.

10 Paraskevopoulou MD, Georgakilas G, Kostoulas N, Vlachos IS, Vergoulis T, Reczko M, Filippidis C, Dalamagas $\mathrm{T}$ and Hatzigeorgiou AG: DIANA-microT web server v5.0: service integration into miRNA functional analysis workflows. Nucleic Acids Res 41: 169-173, 2013.

11 Reczko M, Maragkakis M, Alexiou P, Grosse I and Hatzigeorgiou AG: Functional microRNA targets in protein coding sequences. Bioinformatics 28: 771-776, 2012.

12 Vlachos IS, Kostoulas N, Vergoulis T, Georgakilas G, Reczko M, Maragkakis M, Paraskevopoulou MD, Prionidis K, Dalamagas T, and Hatzigeorgiou AG: DIANA miRPath v.2.0: investigating the combinatorial effect of microRNAs in pathways. Nucleic Acids Res 40: 498-504, 2012.

13 Kanda Y: Investigation of the freely available easy-to-use software 'EZR' for medical statistics. Bone Marrow Transplant 48: 452-458, 2013.

14 Yu G, Li H, Wang J, Gumireddy K, Li A, Yao W, Tang K, Xiao W, Hu J, Xiao H, Lang B, Ye Z, Huang Q and Xu H: miRNA-34a suppresses cell proliferation and metastasis by targeting CD44 in human renal carcinoma cells. J Urol 192: 1229-1237, 2014.

15 Buchler T, Bortlicek Z, Poprach A, Pavlik T, Veskrnova V, Honzirkova M, Zemanova M, Fiala O, Kubackova K, Slaby O, Svoboda M, Vyzula R, Dusek L, Melichar B and Czech Renal Cancer Cooperative Group: Outcomes for patients with metastatic renal cell carcinoma achieving a complete response on targeted therapy: A registry-based analysis. Eur Urol 70: 469-475, 2016.

16 Chang X, Zhang F, Liu T, Yang R, Ji C, Zhao X, Xu L, Liu G and Guo H: Comparative efficacy and safety of first-line treatments in patients with metastatic renal cell cancer: a network meta-analysis based on phase 3 RCTs. Oncotarget 7: 15801-15810, 2016. 
17 Merhautova J, Hezova R, Poprach A, Kovarikova A, Radova L, Svoboda M, Vyzula R, Demlova R and Slaby O: $m i R-155$ and $m i R-484$ are associated with time to progression in metastatic renal cell carcinoma treated with sunitinib. Biomed Res 2015: 941980, 2015.

18 Ellegaard AM, Groth-Pedersen L, Oorschot V, Klumperman J, Kirkegaard T, Nylandsted J and Jäättelä M: Sunitinib and SU11652 inhibit acid sphingomyelinase, destabilize lysosomes, and inhibit multidrug resistance. Mol Cancer Ther 12: 20182030, 2013.

19 Gotink KJ, Broxterman HJ, Labots M, de Haas RR, Dekker H, Honeywell RJ, Rudek MA, Beerepoot LV, Musters RJ, Jansen G, Griffioen AW, Assaraf YG, Pili R, Peters GJ and Verheul HM: Lysosomal sequestration of sunitinib: a novel mechanism of drug resistance. Clin Cancer Res 17: 7337-7346, 2011.

20 Giuliano S, Cormerais Y, Dufies M, Grépin R, Colosetti P, Belaid A, Parola J, Martin A, Lacas-Gervais S, Mazure NM, Benhida R, Auberger P, Mograbi $B$ and Pagès G: Resistance to sunitinib in renal clear cell carcinoma results from sequestration in lysosomes and inhibition of the autophagic flux. Autophagy 11: 1891-1904, 2015 .
21 Sakai I, Miyake H and Fujisawa M: Acquired resistance to sunitinib in human renal cell carcinoma cells is mediated by constitutive activation of signal transduction pathways associated with tumour cell proliferation. BJU Int 112: 211-220, 2013.

22 Gotink KJ, Broxterman HJ, Honeywell RJ, Dekker H, de Haas RR, Miles KM, Adelaiye R, Griffioen AW, Peters GJ, Pili R and Verheul HM: Acquired tumor cell resistance to sunitinib causes resistance in a HT-29 human colon cancer xenograft mouse model without affecting sunitinib biodistribution or the tumor microvasculature. Oncoscience 1: 844-853, 2014.

Received March 28, 2017

Revised April 15, 2017

Accepted April 24, 2017 